\section{Antimicrobial susceptibility of Campylobacter cuniculorum isolated from rabbits reared in intensive and rural farms}

\author{
Silvia Piva, Daniela Florio, Domenico \\ Mion, Renato Giulio Zanoni \\ Department of Veterinary Medical \\ Sciences, Alma Mater Studiorum- \\ University of Bologna, Ozzano dell'Emilia \\ (BO), Italy
}

\section{Abstract}

The present study aimed to investigate the antimicrobial susceptibility in Campylobacter cuniculorum. To do so, 29 isolates from rabbits reared in 18 intensive and 11 rural farms not epidemiologically correlated were tested. Minimum inhibitory concentration of 8 antimicrobial agents was determined using the agar dilution method recommended by the Clinical and Laboratory Standards Institute (Wayne, PA, USA), modified - for what supplements in the base medium and incubation conditions concern - for $C$. cuniculorum isolates. The isolates obtained from rural farming resulted susceptible to all the antimicrobial agents tested, with the exception of one isolate resistant to nalidixic acid. All the isolates obtained from intensively farmed rabbits were sensitive to chloramphenicol and ampicillin; 16 isolates were resistant to tetracycline; 15 to nalidixic acid and erythromycin; 13 and 10 isolates to ciprofloxacin and enrofloxacin, respectively; and only 1 to gentamicin. The resistance of several isolates to macrolides and fluoroquinolones, which are the drugs of choice in treatment of human campylobacteriosis, could pose a risk to human health if a pathogenic role of $C$. cuniculorum was demonstrated.

\section{Introduction}

Campylobacter spp., especially $C$. jejuni and $C$. coli, are considered to be amongst the most prevalent foodborne pathogens associated with sporadic diarrhoea in humans (Engberg et al., 2001; Callicott et al., 2008; Horrocks et al., 2009; Chen et al., 2010). Campylobacter spp. colonise the intestines of food animals and they can contaminate meat during slaughter or post-slaughter processing (Hermans et al., 2011; Mackiw et al., 2012). Although Campylobacter infections are usually self-limiting and do not require antibiotic treatment, in some cases such as prolonged enteritis and septicaemia, antimicrobial treatment is needed. Macrolides and fluoroquinolones are the drugs of choice in treatment of human campylobacteriosis (Van Looveren et al., 2001; Guevremont et al., 2006; Moore et al., 2006), however emergence of resistance to these agents has prompted worries related to their use (Moore et al., 2005). In 2009, Zanoni and colleagues described a new Campylobacter species isolated from rabbit caecal contents named $C$. cuniculorum. So far there are no data on antimicrobial susceptibility in this novel Campylobacter species, so the aim of this study was to define for the first time the antimicrobial susceptibility in C. cuniculorum isolated from rabbits for meat.

\section{Materials and Methods}

A selection of 29 C. cuniculorum isolates from a total of 29 epidemiologically non-correlated rabbits farms during a previous study by Revez et al. (2013) was used for this study: one strain for each farm was randomly selected for the evaluation of antibiotics susceptibility by using agar dilution method. The tested isolates were collected from April 2007 to November 2008 from 29 farms, 27 (18 intensive and 9 rural) were located in 7 different Italian regions while 2 farms (rural) were located in Portugal (Revez et al., 2013). The number of mares in the intensive farms ranged from 300 to 700 subjects; while in rural ones they ranged from 5 to 15 . Information about the region and farm system is reported in Table 1. The minimum inhibitory concentration (MIC) value of ampicillin, ciprofloxacin, chloramphenicol, erythromycin, gentamicin, nalidixic acid, enrofloxacin and tetracycline was determined using a modified agar dilution method for $C$. jejuni and related species described by the Clinical and Laboratory Standards Institute (Wayne, PA, USA; CLSI, 2008) in order to be applied to the study of antimicrobial resistance of $C$. cuniculorum. The method was modified as follows: i) the base medium was Nutrient Broth N.2 (Oxoid, Basingstoke, UK) supplemented with 1.5\% Bacto Agar (Difco-BD, Milan, Italy) and 5\% defibrinated sheep blood; ii) the plates were incubated at $37^{\circ} \mathrm{C} \pm 1$ under microaerobic atmosphere with hydrogen for 72 h. These changes have been introduced because several isolates of $C$. cuniculorum did not grow on Mueller Hinton Agar with 5\% defibrinated sheep blood; moreover, the reading times were increased since visible growth does not appear before $72 \mathrm{~h}$ of incubation for this species. All antimicrobial agents were purchased from Sigma-Aldrich (Saint Louis, MO, USA) and the antibiotic concentrations ranged from 0.015 to $128 \mu \mathrm{g} \mathrm{mL} \mathrm{mL}^{-1}$. C. jejuni ATCC 33560 , Escherichia coli ATCC 25922, and
Correspondence: Silvia Piva, Department of Veterinary Medical Sciences, University of Bologna, via Tolara di Sopra 50, 40064 Ozzano dell'Emilia (B0), Italy.

Tel: +39.051.2097064 - Fax: +39.051.2097039.

E-mail: silvia.piva@unibo.it

Key words: Campylobacter cuniculorum; Antibiotic resistance; Rabbits.

Received for publication: 23 February 2016.

Revision received: 25 March 2016.

Accepted for publication: 27 March 2016.

This work is licensed under a Creative Commons Attribution-NonCommercial 4.0 International License (CC BY-NC 4.0).

(C) Copyright S. Piva et al., 2016

Licensee PAGEPress, Italy

Italian Journal of Food Safety 2016; 5:5829

doi:10.4081/ijfs.2016.5829

Staphylococcus aureus ATCC 29213 were used as a quality control strains. In this study the MICs resistance breakpoints for Campylobacter spp. were those used by the National Antimicrobial Resistance Monitoring System (Atlanta, GA, USA; NARMS) as reported in the US Centers for Disease Control NARMS Annual Report (2010) for Campylobacter spp. for chloramphenicol, ciprofloxacin, nalidixic acid and tetracycline. For ampicillin, erythromycin and gentamicin we adopted the breakpoints described by CLSI (2008) for Campylobacter spp. Since a standardised MIC breakpoint for enrofloxacin is not available for Campylobacter spp., we adopted the value indicated by CLSI (2008) for Enterobacteriaceae. The following resistance breakpoints were used: ampicillin $\geq 32$, chloramphenicol $\geq 32$, ciprofloxacin $\geq 4$, enrofloxacin $\geq 4$, erythromycin $\geq 32$, gentamicin $\geq 8$, nalidixic acid $\geq 64$, and tetracycline $\geq 16$.

\section{Results}

The results of MIC testing for each single isolate are reported in Table 1, while the distribution of MIC values of the 29 isolates tested is shown in Table 2. A monomodal distribution (with one distinct peak) for the MICs was found for all the antibiotics tested except for ciprofloxacin, enrofloxacin and erythromycin, which showed a bimodal (with two distinct peaks) appearance with a second peak at 4$128,1-16$ and $128-\geq 128 \mu \mathrm{g} \mathrm{mL} \mathrm{m}^{-1}$, respectively. The bimodal distribution means that there are two distinct microbial populations, showing a different behaviour to antimicrobials, suggesting an acquired resistance. Noteworthy 15 and 
13 isolates, all obtained from rabbits reared in intensive farms, showed a resistance to erythromycin and enrofloxacin characterised by a bimodal frequency with a high level of MIC in the second peak.

\section{Discussion}

This is the first report on the antimicrobial susceptibility of $C$. cuniculorum. Revez et al.
(2013), investigating the occurrence of $\varepsilon$-proteobacteria in caecal contents of rabbits, isolated $C$. cuniculorum in 83 out of 87 animals tested, in a large number of colonies, suggesting that this microorganism, when present,

Table 1. Results of the minimum inhibitory concentration test of the twenty-nine Campylobacter cuniculorum isolates from rabbits with relative information on locality (region) and farm system.

\begin{tabular}{|c|c|c|c|c|c|c|c|c|c|c|}
\hline \multirow{3}{*}{$\begin{array}{l}\text { Farm } \\
\text { code } \\
1\end{array}$} & \multirow[t]{2}{*}{ Region } & \multirow[t]{2}{*}{ Farm system } & \multicolumn{8}{|c|}{ MIC values ( $\mathrm{g} \mathrm{mL}^{-1}$ ) of 8 antimicrobials } \\
\hline & & & CIP & NA & ENR & AMP & TE & GM & $\mathbf{E}$ & $\mathrm{C}$ \\
\hline & Emilia-Romagna & Rural & 0.125 & 16 & 0.06 & 2 & 4 & 0.25 & 1 & 16 \\
\hline 9 & Emilia-Romagna & Rural & 0.5 & 32 & 0.06 & 4 & 8 & 0.125 & 1 & 16 \\
\hline 21 & Beira litoral (PT) & Rural & 0.125 & 32 & 0.125 & 4 & 8 & 0.06 & 1 & 16 \\
\hline 22 & Algarve (PT) & Rural & 0.25 & 16 & 0.125 & 16 & 4 & 0.125 & 0.5 & 8 \\
\hline 23 & Emilia-Romagna & Rural & 0.25 & 32 & 0.06 & 16 & 8 & 0.125 & 1 & 16 \\
\hline 24 & Emilia-Romagna & Rural & 0.5 & 64 & 0.125 & 4 & 4 & 0.125 & 2 & 16 \\
\hline 25 & Emilia-Romagna & Rural & 0.25 & 32 & 0.06 & 16 & 4 & 0.25 & 4 & 16 \\
\hline 26 & Emilia-Romagna & Rural & 0.125 & 32 & 0.06 & 1 & 4 & 0.06 & 0.5 & 8 \\
\hline 27 & Lazio & Rural & 0.25 & 32 & 0.125 & 8 & 4 & 0.125 & 1 & 16 \\
\hline 28 & Lazio & Rural & 0.125 & 32 & 0.06 & 2 & 4 & 0.03 & 1 & 8 \\
\hline 29 & Lazio & Rural & 0.125 & 32 & 0.06 & 2 & 4 & 0.03 & 1 & 8 \\
\hline 2 & Piemonte & Intensive & 0.125 & 128 & 0.06 & 8 & 32 & 2 & $>128$ & 8 \\
\hline 3 & Emilia-Romagna & Intensive & 64 & $>128$ & 16 & 2 & 32 & 4 & $>128$ & 8 \\
\hline 4 & Emilia-Romagna & Intensive & 0.25 & 128 & 0.06 & 16 & 64 & 8 & $>128$ & 8 \\
\hline 5 & Emilia-Romagna & Intensive & 32 & $>128$ & 8 & 8 & 4 & 0.03 & 1 & 16 \\
\hline 6 & Veneto & Intensive & 32 & 128 & 4 & 8 & 32 & 1 & $>128$ & 16 \\
\hline 7 & Veneto & Intensive & 32 & $>128$ & 8 & 8 & 32 & 4 & $>128$ & 8 \\
\hline 8 & Sicilia & Intensive & 0.5 & 64 & 0.125 & 8 & 32 & 1 & $>128$ & 16 \\
\hline 10 & Emilia-Romagna & Intensive & 8 & $>128$ & 2 & 8 & 16 & 0.03 & $>128$ & 4 \\
\hline 11 & Emilia-Romagna & Intensive & 64 & $>128$ & 8 & 4 & 32 & 0.5 & 0.5 & 16 \\
\hline 12 & Friuli Venezia Giulia & Intensive & 64 & $>128$ & 8 & 8 & 32 & 1 & $>128$ & 16 \\
\hline 13 & Veneto & Intensive & 128 & $>128$ & 16 & 8 & 32 & 4 & $>128$ & 16 \\
\hline 14 & Veneto & Intensive & 16 & 64 & 1 & 2 & 8 & 0.125 & 1 & 16 \\
\hline 15 & Marche & Intensive & 4 & 128 & 4 & 0.5 & 16 & 2 & $>128$ & 4 \\
\hline 16 & Veneto & Intensive & 16 & 16 & 2 & 1 & 16 & 0.5 & 128 & 8 \\
\hline 17 & Veneto & Intensive & 32 & 128 & 8 & 16 & 64 & 4 & $>128$ & 8 \\
\hline 18 & Marche & Intensive & 0.125 & 16 & 0.03 & 2 & 32 & 0.03 & $>128$ & 2 \\
\hline 19 & Emilia-Romagna & Intensive & 32 & $>128$ & 4 & 2 & 64 & 0.5 & $>128$ & 8 \\
\hline 20 & Lazio & Intensive & 0.5 & 32 & 0.125 & 16 & 32 & 0.125 & $>128$ & 8 \\
\hline
\end{tabular}

MIC, minimum inhibitory concentration; PT, Portugal; CIP, ciprofloxacin; NA, nalidixic acid; ENR, enrofloxacin; AMP, ampicillin; TE, tetracycline; GM, gentamicin; E, erythromycin; C, chloramphenicol.

Table 2. Distribution of minimum inhibitory concentrations of twenty-nine Campylobacter cuniculorum isolates and minimum inhibitory concentration 50 and 90 values.

\begin{tabular}{|c|c|c|c|c|c|c|c|c|c|c|c|c|c|c|c|c|c|}
\hline \multirow[t]{2}{*}{ Antimicrobials } & \multicolumn{17}{|c|}{ Number of Campylobacter cuniculorum isolates with MIC $\left(\mu \mathrm{g} \mathrm{mL}^{-1}\right)$} \\
\hline & $\leq 0.015$ & 0.03 & 0.06 & 0.125 & 0.25 & 0.5 & 1 & 2 & 4 & 8 & 16 & 32 & 64 & 128 & $>128$ & MIC 50 & MIC 90 \\
\hline Ampicillin & & & & & & 1 & 2 & 7 & 4 & 9 & 6 & & & & & 8 & 16 \\
\hline Chloramphenicol & & & & & & & & 1 & 2 & 12 & 14 & & & & & 8 & 16 \\
\hline Ciprofloxacin & & & & 7 & 5 & 4 & & & 1 & 1 & 2 & 5 & 3 & 1 & & 0.5 & 64 \\
\hline Enrofloxacin & & 1 & 9 & 6 & & & 1 & 2 & 3 & 5 & 2 & & & & & 0.125 & 8 \\
\hline Erythromycin & & & & & & 3 & 9 & 1 & 1 & & & & & 1 & 14 & 64 & $>128$ \\
\hline Gentamicin & & 5 & 2 & 7 & 2 & 3 & 3 & 2 & 4 & 1 & & & & & & 0.25 & 4 \\
\hline Nalidixic acid & & & & & & & & & & & 4 & 9 & 3 & 5 & 8 & 64 & $>128$ \\
\hline Tetracycline & & & & & & & & & 9 & 4 & 3 & 10 & 3 & & & 16 & 32 \\
\hline
\end{tabular}

MIC, minimum inhibitory concentration. 
colonises the caecum at a high concentration (Revez et al., 2013).

The results of this study, even if not statistically analysed, show high resistant level in $C$. cuniculorum isolated from rabbits reared in intensive farm; indeed, all the 18 isolates from intensive farms resulted resistant to two antibiotics at least. On the contrary, out of the 11 isolates from rural farms, only one resulted resistant to only one antibiotic. These data suggest that modern food animal production managements contribute to produce favourable conditions for the emergence and spread of antibiotic resistant bacteria due to the larger use of antimicrobial agents to control infections. Moreover, trends in antimicrobial resistance have shown a clear association between use of antibiotics in the veterinary industry and resistant isolates of Campylobacter spp. in humans (Alfredson and Korolick, 2007; Angulo et al., 2004).

Nowadays, there is no information on the pathogenic role of this new Campylobacter species, but the importance of antibiotic resistances that could be transmitted to other pathogen Campylobacter species may represent a risk of human concerns. Resistance to fluoroquinolones and macrolides is mediated by chromosomal mutations not transferable to other bacteria. However, the resistance to tetracycline show the potential for resistance transmission to other Campylobacter species (Aarestrup and Engberg, 2001).

In the present study, fluoroquinolone and macrolide showed a bimodal distribution suggesting an acquired resistance due to a gene mutation. Fluoroquinolones and macrolides are the antimicrobials chosen for the treatment of campylobacteriosis; in Campylobacter spp., fluoroquinolone resistance seems to be due to mutations in the gyrA gene encoding part of the GyrA subunit of DNA gyrase (Aarestrup and Engberg, 2001; Alfredson and Korolik, 2007). Relatively to macrolide resistance in Campylobacter species, modification of the target, represented by point mutation or methylation of $23 \mathrm{~S} r R N A$ gene, seems to be the main mechanism involved. As far as $C$. cuniculorum is concerned, in-depth studies should be performed to clarify molecular mechanisms by sequencing the involved genes in C. cuniculorum isolates and performing comparisons of these sequences in sensible and resistant isolates. For all the other antibiotics tested, a monomodal distribution of MIC values was observed and, on the basis of the clinical breakpoints, we may assume that all $C$. cuniculorum isolates are sensitive to chloramphenicol and ampicillin. Sixteen out of the 29 tested isolates resulted resistant to nalidixic acid and tetracycline. Regarding the nalidixic acid, 12 out of 16 isolates resistant to nalidixic acid were resistant to ciprofloxacin too, so, the quinolone resistance-determining region of gyrA gene could be involved in the acquisition of this resistance. With regard to tetracycline resistance, it is found to be located in $C$. jejuni and $C$. coli on a self-transmissible plasmid encoding a ribosomal protection protein, designated as tet $(O)$, thus suggesting a potential role of $C$. cuniculorum in passing this resistance to other Campylobacter species.

\section{Conclusions}

In conclusion, for the first time this study shows data on $C$. cuniculorum antimicrobial susceptibility, suggesting a probable higher risk of antibiotic resistance in rabbits reared in intensive farms than those reared in rural farms. The evidence of tetracycline resistance in $C$. cuniculorum that could be transmitted to other human pathogen Campylobacter species may represent a risk for human health.

\section{References}

Aarestrup F, Engberg J, 2001. Antimicrobial resistance of thermophilic Campylobacter. Vet Res 32:311-21.

Alfredson DA, Korolik V, 2007. Antibiotic resistance and resistance mechanisms in Campylobacter jejuni and Campylobacter coli. FEMS Microbiol Lett 277:123-32.

Angulo FJ, Nunnery JA, Bair HD, 2004. Antimicrobial resistance in zoonotic enteric pathogens. Rev Sci Tech 23:485-96.

Callicott KA, Hardardottir H, Georgsson F, Reiersen J, Frioriksdottir V, Gunnarsson E, Michel P, Bisaillon J, Kristinsson KG, Briem H, Hiett KL, Needleman DS, Stern NJ, 2008. Broiler Campylobacter contamination and human campylobacteriosis in Iceland. Appl Environ Microb 74:6483-94.

Chen X, Naren GW, Wu CM, Wang Y, Dai L, Xia LN, Luo PJ, Zhang Q, Shen JZ, 2010. Prevalence and antimicrobial resistance of Campylobacter isolates in broilers from China. Vet Microbiol 144:133-9.

CLSI, 2008. Performance standards for antimicrobial disk and dilution susceptibility tests for bacterial isolated from animals. CLSI document M31-A3. Clinical and Laboratory Standards Institute, Wayne, PA, USA.

Engberg J, Aarestrup FM, Taylor DE, Gerner-
Smidt P, Nachamkin I, 2001. Quinolone and macrolide resistance in Campylobacter jejuni and C. coli: resistance mechanisms and trends in human isolates. Emerg Infect Dis 7:24-34.

Guevremont E, Nadeau E, Sirois M, Quessy S, 2006. Antimicrobial susceptibilities of thermophilic Campylobacter from humans, swine, and chicken broilers. Can J Vet Res 70:81-6.

Hermans KM, Deun KV, Martel A, Immerseel FV, Messens W, Heyndrickx M, Haesenbrouck F, Pasmans F, 2011. Colonization factors of Campylobacter jejuni in the chicken gut. Vet Res 42:1-14.

Horrocks SM, Anderson RC, Nisbet DJ, Ricke SC, 2009. Incidence and ecology of Campylobacter jejuni and Campylobacter coli in animals. Anaerobe 15:18-25.

Mackiw E, Korsak D, Rzewuska K, Tomczuk K, Rozynek E, 2012. Antibiotic resistance in Campylobacter jejuni and Campylobacter coli isolated from food in Poland. Food Control 23:297-301.

Moore JE, Barton MD, Blair IS, Corcoran D, Dooley JSG, Fanning S, Kempff I, Lastovica AJ, Lowery CJ, Matsuda M, McDowell DA, McMahon A, Millar BC, Rao JR, Rooney PJ, Seal BS, Snelling WJ, Tolba 0, 2006. The epidemiology of antibiotic resistance in Campylobacter. Microbes Infect 8:1955-66.

Moore JE, Corcoran D, Dooley JS, Fanning S, Lucey B, Matsuda M, McDowell DA, Megraud F, Millar BC, 0'Mahony R, 0'Riordan L, O'Rourke M, Rao JR, Rooney PJ, Sails A, Whyte P, 2005. Campylobacter. Vet Res 36:351-82.

NARMS, 2010. NARMS retail meat annual report, 2010. Available from: www.fda. gov/downloads/AnimalVeterinary/SafetyHe alth/AntimicrobialResistance/NationalAnti microbialResistanceMonitoringSystem/U CM293581.pdf

Revez J, Rossi M, Piva S, Florio D, Lucchi A, Parisi A, Manfreda G, Zanoni RG, 2013. Occurrence of -proteobacterial species in rabbits (Oryctolagus cuniculus) reared in intensive and rural farms. Vet Microbiol 162:288-92.

Van Looveren M, Daube G, De Zutter L, Dumont JM, Lammens C, Wijdooghe M, Vandamme P, Jouret M, Cornelis M, Goossens H, 2001. Antimicrobial susceptibilities of Campylobacter strains isolated from food animals in Belgium. $\mathrm{J}$ Antimicrob Chemoth 48:235-40.

Zanoni RG, Debruyne L, Rossi M, Revez J, Vandamme P, 2009. Campylobacter cuniculorum sp. nov., from rabbits. Int J Syst Evol Micr 59:1666-71. 